\title{
Entrevista a Elina Aguiar
}

Comité de Redacción: Asi que bueno, venimos a entrevistarte sobre tu relación con Gilou y lo que nos podés transmitir de lo que fue el trabajo de Gilou en el área de los derechos humanos.

Elina Aguiar: Buenisimo, antes que nada yo no era discipula de Gilou, Gilou no tenía discípulos [risas]. Si no que éramos muy amigas, de salir al cine, de ir al teatro, a exposiciones de arte, todo lo relacionado con la cultura le interesaba. Yo formaba parte de la APDH, la Asamblea Permanente por los Derechos Humanos, en septiembre del 84 hicimos una convocatoria en el teatro San Martín con el tema: “Los efectos de la represión, la dimension de lo psíquico”. Eran momentos donde todavía el miedo estaba presente. Cómo sería que no se hablaba mucho en las instituciones psicoanalíticas de la dictadura y sus efectos y cuando lo invito a un colega que había sido profesor mío y le digo el título de la convocatoria me contesta "claro, jla represión desde la neurosis", no no, le digo, ¡se trata de la represión política!. No vino a la Jornada.

Eran varios los panelistas que habíamos pensado en invitar, entre ellos me acuerdo de Rafael Paz, quien no aceptó participar del panel porque los tiempos estaban díficiles y era mejor no aparecer. Sin embargo la invitamos a Gilou y a otros colegas que gustosos aceptaron. Gilou presentó el trabajo "Matar la muerte" (que se encuentra en Internet) que a mí me dio todo un conocimiento de ella y de ahí en más, nos fuimos conociendo más y nos hicimos amigas, la había conocido en el Hospital de Clínicas en la especialización pero era alguien que pasaba y nada más. Gilou era, no sé si la conocieron personalmente, tenía una potencia para hablar, tenía una fuerza, una convicción y una vitalidad muy especial, Gilou cuando se metía con algo, se metía de verdad. Su interés por los derechos humanos data desde los años de López Rega 74-75 y junto con los abogados Rodolfo Ortega Peña y Eduardo Luis Duhalde empezaron a hacer amparos y ella como psicoanalista acompañaba a los familiares, a los abogados, los abogados también estaban amenazados, había varios más. Entonces escribieron juntos un libro denunciando las situaciones que se vivían, nadie sabe de este libro, bueno quizás haya sido quemado, lamentablemente no quedó copia de ese libro.

CdR: ¿Cómo se llamaba?

Elina: El Libro Negro de los Derechos Humanos, y yo no lo consegui, le pregunte a la hija y no sabía nada.

$C d R:$ ¿Y fue escrito en ese momento?

Elina: Fue escrito en ese momento por Ortega Peña y Gilou, creo que habría otros abogados más. Qué pena porque era un libro de denuncias con todos los “ habeas corpus”, con reflexiones de ella, o sea, que ella comenzó tempranamente a ocuparse públicamente de los derechos humanos. Algunas amigas y yo lo sabíamos pero nadie tiene el libro, yo tampoco lo vi, ni siquiera ella lo tenía. Ella se exilió en México y allí estuvo también su gran amiga Marie Langer, pero no sé que habrá pasado con el ibro.

Bueno, Gilou no fue médica enseguida, primero estudió matemáticas, cuando estaba por terminar la carrera nace su primer hijo y luego su hija, luego se separa. Gilou no terminó matematicas, empezó filosofia y trataba de mantenerse económicamente haciendo vestidos geométricos muy creativos y muy fáciles de hacer para la señoras de la alta sociedad, cosía vestidos 
sencillos. Por esas épocas comenzó su interés por el psicoanálisis y entonces un amigo le dijo que era conveniente estudiar medicina para ser psicoanalista. Es así entonces que ella estudia medicina, se recibió de médica. Lo que la impactó de la medicina no eran los cadáveres, sino el contacto con el Hospital, con el desamparo absoluto, con el otro reducido a resto y ahí empieza a pergeñar la idea del Gran Otro Social desubjetivante, esto marcó su accionar en la clínica. Trabajando con familias, con niños y con sus madres desamparadas, ella sostenía que es imposible que estas familias amparasen a sus niños porque ellas mismas no estaban amparadas por ese Otro Social dado que teniendo su vida en estado de inseguridad absoluta, no se puede amparar a otro. Alguien en condiciones desubjetivantes no puede proveer subjetivación cuando desde el Estado, desde el Gran Otro Social solo se brinda desamparo. Esto marcó su práctica clínica.

Antes de exiliarse trabajaba en la cátedra de Medicina del Trabajo en la época del decanato de Mario Testa, se peleó con los laboratorios, porque ella sostenía que el derecho humano a la salud era para todos.

En el 54 ingresó a la A.P.A. y en el 71 siendo "analista didacta”, rompió con la A.P.A. Durante toda su vida, ella se esmeró en no en aplicar el psicoanalisis a los derechos humanos, sino en hacer trabajar el psicoanalisis con lo político y lo social, hacer trabajar el psicoanalisis en los derechos humanos.

En el año 1976, Diego García Reinoso, su segundo marido fue amenazado de muerte por teléfono y ella trabajando en un grupo terapéutico dijo: "sospecho que uno de los pacientes es de los servicios", entonces se dijo “en estas condiciones yo no puedo trabajar". Ellos se exilian en México y es convocada por el Ministerio o Secretaría de Trabajo de México: ella trabaja velando por las condiciones físicas y mentales de los trabajadores. Ella decía riéndose "estando desde el patrón -Ministerio de Trabajo- trabajaba por el bienestar de los trabajadores". También tenía cátedras en la UNAM.

En el año 82 deciden volver a la Argentina, casi le toca al hijo menor hacer el servicio militar obligatorio y estar en Malvinas y ella recordaba su inmensa angustia pensando que habían vuelto prematuramente. Por suerte a Martín no le tocó hacer el servicio militar, una gran cosa para ella, porque hubiera sido tremendo. El desexilio le costó mucho, acá todavía era vista por algunos como subversiva y entonces era peligroso estar con ella. Algunos colegas le derivaban pacientes, otros no por ser la "zurdita”, no le fue fácil, pero luego se volvió a instalar profesionalmente y era consultada por su saber y su saber proveniente de su actuación profesional en el exilio.

En el año 1990 la invito a formar parte del Consejo de Presidencia de la APDH y lo primero que me dijo fue "mirá que no me gustan las instituciones, yo estoy en contra de las instituciones porque enseguida lo instituyente se convierte en instituido, se burocratiza y se pierde todo". Y ahí empezamos a ser muy amigas, empecé a conocer su obra y francamente me abrió todo un panorama, aprendí su manera de pensar. Compartimos con Gilou un panel en el Congreso Metropolitano de Psicología, junto con Ignacio Martín Baró, un psicólogo jesuita que luego fue masacrado, ametrallado en El Salvador junto con otros jesuítas durante el gobierno dictatorial. Yo no lo conocía y tuve la suerte de conocerlo a él y sus conceptos de la "resignación aprendida" de los pueblos que se someten pasivamente. Gilou expuso sobre las consecuencias psíquicas de la lógicas de las tranformaciones sociales, en ese ejemplo que ella da citando el trabajo de unos psicologos de San Pablo, ¿recuerdan el ejemplo? 


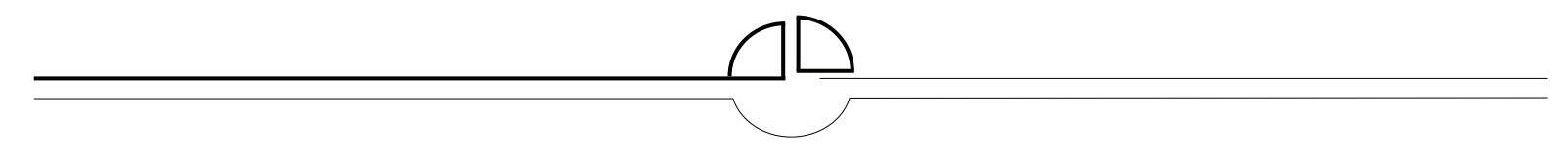

CdR: Sí, sí el de la plaza.

Elina: El de la plaza sí, cómo el contacto con esas personas consideradas como resto, parias de la sociedad, desde la ternura y el respeto puede ser humanizante. Eso a mí me fue útil y desde APDH, desde la Comisión de Salud Mental organizamos grupos para jugar con personas que viven en la calle, éramos tres colegas, otro por recibirse, mi hermano era abogado, en fin, encuentros periódicos para compartir con la gente que vivía en la calle, jugando distintos juegos de mesa, en una plaza con bancos y mesitas y bien arbolada, cerca de los comedores comunitarios. Esto surgió gracias a la lectura de aquel trabajo de Gilou en el Congreso Metropolitano de Psicología.

Nos inspiramos en Gilou, después le conté la idea y le pareció buenísima, propagandizábamos en los comedores para que la gente viniera porque la gente que vive en a calle es deambulante, un día esta acá otro día esta allá. Era un trabajo humanizante, subjetivante con los "restos sociales". Ella quiso incorporarse al equipo, porque era la preocupación de ella permanente. Pero ya estaba muy grande para estar a la intemperie varias horas con fríos y calores a veces exesivos en la plaza.

En la APDH ella se encargó de la Comisión de Cultura. Es así que en los años 2000/2001, trabajamos en conferencias que hacíamos, el Movimiento MAR, ¿lo conocen?. MAR: "Movimiento Argentina Resiste", trabajamos mucho, llamábamos invitados, hicimos una serie de conferencias, Gilou era la que coordinaba y se invitaba a economistas, a filósofos, a antropólogos para reflexionar sobre lo que estaba sucediendo. Trabajabamos mucho, yo formaba parte en ese tiempo de la Comisión de Cultura, con preguntas a los oradores, trabajábamos sobre las preguntas a hacer nosotros y el público participaba muchísimo. Eso fue muy muy importante. Y después en la Comisión de Cultura también trabajó en el Colegio Nacional de Buenos Aires, en la época de Menem, nuevamente con este esquema de paneles y mucha participación del público y lo hacíamos a propósito en el Nacional de Buenos Aires porque algún chico del contraturno podía asistir ahí y también se hacían preguntas y replanteos. Fue interesante ese intercambio con actrices, con todas las personas de la cultura, porque ella decía que cultura era llevarle al pueblo, a los que "no son nadie"(refiriendose al anonimato), lo que acontece y lo que nos humaniza con solo intercambiar algo. Así fue que empezaron a trabajar, en la Comision de Cultura llevando obras de teatro que tenían que ver con algo de derechos humanos o de violencia en contra de los los jóvenes, donde actrices y actores iban y lo representaban en barrios, en escuelas y fue un trabajo como de dos o tres años muy importantes. Digamos para gente del Gran Buenos Aires que nunca iba al teatro iban actores, actrices afines a derechos humanos. Era una participación que movilizaba y surgían perspectivas y redes. Gilou siempre estuvo inquieta por estas cosas.

En el Encuentro que se denominó "Los Estados Generales del Psicoanalisis" (en La Sorbona en París) en el que Gilou participó e impulsó su realización, ella afirmaba que el inconsciente social si uno está dispuesto a escucharlo y escucha lo social y lo político, están. Basta que nosotros pongamos la oreja o la atención para escuchar, esto está en todas partes. Fue muy rica su ponencia y debate, supongo que deben tener el escrito de ella.

Algo que me olvidé de decirles, que por los años $74 \mathrm{creo}$, ella junto con otros formaron el CDI -porque en la época, yo fui alumna de ahí-, era el Centro de Docencia e Investigación. Lo interesante es que enseñaba psicoanálisis no desligado de lo social, o sea se estudiaba psicoanálisis y también se discutía políticamente psicoanálisis, no era una cosa fácil y no era pago. No era 